OPEN ACCESS

Edited by:

Hideyuki Doi,

University of Hyogo, Japan

Reviewed by:

Rentao Liu,

Ningxia University, China

Ender Makineci,

Istanbul University-Cerrahpasa

Turkey

${ }^{*}$ Correspondence:

Haitao Wu

wuhaitao@iga.ac.cn

Specialty section:

This article was submitted to

Conservation and Restoration

Ecology,

a section of the journa

Frontiers in Ecology and Evolution

Received: 28 June 2021

Accepted: 23 September 2021

Published: 21 October 2021

Citation:

Zhang $H$, Sun X, LiU D, WU H and Chen $H$ (2021) Air Warming and Drainage Influences Soil

Microarthropod Communities.

Front. Ecol. Evol. 9:731735.

doi: $10.3389 /$ fevo.2021.731735

\section{Air Warming and Drainage Influences Soil Microarthropod Communities}

\author{
Hui Zhang ${ }^{1,2,3}$, Xin Sun ${ }^{4,5}$, Dong Liu' ${ }^{1}$, Haitao Wu ${ }^{1 *}$ and Huai Chen ${ }^{2}$ \\ ${ }^{1}$ Key Laboratory of Wetland Ecology and Environment, Northeast Institute of Geography and Agroecology, Chinese \\ Academy of Sciences, Changchun, China, ${ }^{2}$ Key Laboratory of Mountain Ecological Restoration and Bioresource Utilization \& \\ Ecological Restoration and Biodiversity Conservation Key Laboratory of Sichuan Province, Chengdu Institute of Biology, \\ Chinese Academy of Sciences, Chengdu, China, ${ }^{3}$ University of Chinese Academy of Sciences, Beijing, China, ${ }^{4}$ Key \\ Laboratory of Urban Environment and Health, Institute of Urban Environment, Chinese Academy of Sciences, Xiamen, \\ China, ${ }^{5}$ J.F. Blumenbach Institute of Zoology and Anthropology, University of Göttingen, Göttingen, Germany
}

The degradation of wetlands due to climate change is of critical concern to human beings worldwide. Little is known about the potential synergistic effects of simultaneous water level reduction and warming on the underground wetland ecosystems. We conducted a 5-month field experiment in the Sanjiang Plain, utilizing open-top chambers and water level automatic control systems to investigate such synergistic effects. Soil springtails (Collembola) and mites (Acari) in the top $(0-20 \mathrm{~cm})$ soil layers were sampled to calculate their density, diversity, and to screen for indicator species. Warming significantly influenced soil springtail communities, slightly increasing the total density and total abundance under the natural water level while reducing them under a constant water level. In addition, Anurida maritima and Vertagopus laricis, two indicators for the natural water level, had the highest densities in the natural water level treatment and under the combined treatment of warming and natural water level, respectively. Cheiroseius sinicus and Malaconothrus tardus had the highest densities in warming under the $0 \mathrm{~cm}$ water level, significantly higher than the other three treatments. This study also revealed the importance of maintaining fluctuating water levels for microarthropod communities influenced by global warming, providing a theoretical basis for water level control in wetland restoration.

Keywords: climate change, collembola, mites, indicator species, wetland restoration

\section{HIGHLIGHTS}

- Air warming increased the density and richness of springtails (Collembola), while no significant effects on the density and richness of soil mites (Acari).

- Springtails were more sensitive to warming and drainage than mites.

- Anurida maritima (springtails) and Vertagopus laricis (springtails) had the highest densities in the natural water level and warming under the natural water level, respectively. Besides, Cheiroseius sinicus (mites) and Malaconothrus tardus (mites) had the highest densities in warming under the $0 \mathrm{~cm}$ water level. These four indicator species characterized warming and water level changes in wetlands.

- Natural water level fluctuations are important for soil microarthropods protection. 


\section{INTRODUCTION}

Soil fauna are a crucial part of the terrestrial biosphere, and plays an important role in ecosystem function and plant community dynamics (Brussaard, 1998; Geisen and Bonkowski, 2018; Phillips et al., 2019; van den Hoogen et al., 2019; Hallam and Hodson, 2020; Oliverio et al., 2020). Driven by resource heterogeneity, nutrient availability, and abiotic conditions, they could impose direct or indirect and positive or negative feedbacks on aboveground biology by altering rates of nutrient mineralization and the spatial distribution of nutrient availability, rhizospheric hormones and the soil environment (Wang and Ran, 2008). The composition and diversity of soil fauna are closely related to soil properties (physical, chemical, and microbial characteristics), vegetation, and climate (Wardle et al., 2005; Liu et al., 2012; Phillips et al., 2020; Vazquez et al., 2020), among which some sensitive species can also act as indicators to indicate environmental changes (Liang et al., 2001; Sun et al., 2021). It is noteworthy that changes in composition and distribution patterns of soil fauna are likely to impact ecosystem processes and functions (Koltz et al., 2018).

Among soil fauna, soil microarthropods (most fungi/detritivores) such as Collembola, oribatid mites (Acari: Oribatida), and enchytraeids (Oligochaeta: Enchytraeidae) take part in important ecosystem functions such as decomposition, nutrient mobilization, soil mixing, and aggregate formation (Lindberg, 2003; Semenina and Tiunov, 2020). Climate change impacts soil fauna's growth, development, and reproduction, impacting soil microarthropod communities' abundance, and composition, by altering the soil microenvironment. Climate change can also indirectly influence the soil microarthropod communities' structure by changing the resource availability and composition of the soil food web (Kardol et al., 2011; Zhang and $\mathrm{Wu}, 2020$ ).

The effect of warming on soil microarthropods is controversial, as some studies have found that warming significantly reduced the biomass and diversity of springtails (Makkonen et al., 2011; Chang et al., 2019), as well as significantly changing the composition and diversity of soil fauna (Briones et al., 2009; Kardol et al., 2011). In contrast, others have found that warming either increased the total abundance of springtails (Orchesellides) in grasslands of the Songnen Plain, northeast China (Yan et al., 2015) or had no significant effect on the abundance of soil collembola and mites. The different results were possibly related to water content of ecosystems. In humid area, the warming effect was positive or insignificant. However, in relatively arid areas, warming had a negative effect on soil microarthropods, and the variation of precipitation often had a more significant effect on soil microarthropods than warming. For example, one study conducted on a semiarid grassland in Duolun County showed that an increase in rainfall significantly increased the abundance of soil mites and springtails, but warming had no significant effect on soil microarthropods (Wu et al., 2014). Drought increased the abundance of soil microarthropods while reducing their biomass, it also increased the abundance of small mites (body length $0.20 \mathrm{~mm}$ ), and decreased the abundance of large mites (body length $>0.40 \mathrm{~mm}$ ) in the sandy forest soils (the water level is between 5 and 30\%) (Xu et al., 2012). In comparison, warming only slightly affected the animal population (Xu et al., 2012). This was similar to a meta-analysis that identified that the soil microbiota responded more strongly to changes in precipitation than warming (Blankinship et al., 2011). Nevertheless, other studies have found that changes in precipitation can have no significant impact on soil microarthropods (Kardol et al., 2011; Darby and Neher, 2012).

Wetlands provide critical ecosystem functions, including water storage and flood regulation, water quality purification, and local climate regulation. However, the annual average temperature of the Sanjiang Plain and the average temperature of the growing season has increased over the past 60 years, with projections to rise continuously over the next 30 years (Liu, 2016; Meng, 2016). Concurrently, the water levels of the marsh have declined significantly, and the ecosystem has degraded under human drainage disturbance and global change. Yet, research into the relationships between climate change and vegetation coverage, phenology, NDVI (the Normalized Difference Vegetation Index), and the carbon budget of the Sanjiang Plain is limited (Liu et al., 2019; Shen et al., 2019a,b; Zhang et al., 2019). There is also insufficient research into the potential impact of climate warming and drainage on soil microarthropods in the marsh of the Sanjiang Plain.

In this study, we conducted a 5-month simulation experiment of warming and drainage on the marsh of the Sanjiang Plain. We examined the influence of warming and wetland drainage on soil microarthropod community composition, diversity, and vertical distribution. The influence of mild drainage on the wetland soil ecosystem provides a theoretical basis for further understanding how these important and fluctuating abiotic effects can influence wetland soil ecosystems. We also screened soil microarthropod communities for species sensitive to climate change and wetland drainage to enrich the existing wetland evaluation index system. Wetlands are flooded or seasonally flooded areas with higher water content. As a result, we hypothesize that continued drainage will significantly reduce the density and abundance of soil microarthropods, while warming had a positive effect on it. This article mainly focuses on mites and springtails in this article because they are two critical classes of soil fauna and were the most dominant microarthropod groups collected across all treatments.

\section{MATERIALS AND METHODS}

\section{Sample Collection and Processing}

Field samples were collected in August, September, and November of 2018, and data were averaged for these analyses. One soil column was taken from each subplot at each sampling time, immediately wrapped with plastic, and then transported to the laboratory. The soil samples were then placed in a Tullgren-type extractor (Yin, 1992) for $72 \mathrm{~h}$ to extract the soil arthropods. The extracted arthropods were preserved in $70 \%$ ethanol and identified to taxonomic species or morphospecies 
using applicable keys (Balogh and Balogh, 1992; Bellinger et al., 1996-2019; Yin, 1998; Krantz and Walter, 2009).

\section{Site and Plot Description}

The field study was conducted from June 2018 to November 2018, in the marshes at the Sanjiang Mire Wetland Experimental Station $\left(47^{\circ} 13^{\prime \prime} 50^{\prime} \mathrm{N}, 133^{\circ} 13^{\prime \prime} 10^{\prime} \mathrm{E}, 55 \mathrm{~m}\right.$ above the sea level), Chinese Academy of Sciences. The marshes are located in the Sanjiang Plain, a low-lying floodplain, in the Heilongjiang Province, Northeast China. This region has a temperate moist monsoon climate, with a mean annual temperature of $1.9^{\circ} \mathrm{C}$ $\left(-21^{\circ} \mathrm{C}\right.$ in January and $22^{\circ} \mathrm{C}$ in July) and mean annual precipitation of $600 \mathrm{~mm}$ ( $\geq 60 \%$ between July and September). Carex lasiocarpa, Carex pseudocuraica, and Carex meyeriana are the dominant grass species, often grown with co-occurring Deyeuxia angustifolia and Glyceria spiculosa.

In this study, the dominant vegetation in our experiment is C. lasiocarpa, and the water depth in this study area usually fluctuated up and down by $10 \mathrm{~cm}$. Our main purpose was to simulate the fluctuation and the same of water level and found their different impacts on soil fauna communities. So we chose the fluctuation water level of natural wetlands and the constant water level of 0 and $-10 \mathrm{~cm}$. The water levels could be controlled independently, and the specific design and operation of the experiment have been previously described in detail (Tan et al., 2018). In brief, this set of automatic water level control equipment was able to realize the multi-loop automatic control and the function of replenishing and draining simultaneously, consisting of control center, horizontal self-priming centrifugal pump, water ring vacuum pump, electrode hydraulic gauge, water refill solenoid valve, drainage solenoid valve, remote pressure gauge, air compressor, vacuum tank, pneumatic valve, water refill diverters, drainage diverters, water refill pipes, and drainpipes (Figure 1). When the actual water level is lower than the set water level, the water supply system starts to work. Otherwise, the control center will start the drainage system.

Besides, a method of open-top chambers (OTC) was used for the calefaction treatments. The basic function of the OTCs is to increase the air temperature and soil temperature by passively trapping the long wavelength solar radiation. It is also common method for soil fauna researches (Kardol et al., 2011; Makkonen et al., 2011; Yan et al., 2015). In a hexagon-based pyramid shape, the OTC was made of polymethyl-methacrylate sheet [length: width: height $=100: 65$ (top) or 280 (bottom): $230 \mathrm{~cm}$ ]. Each chamber had a door $(100 \mathrm{~cm}$ width and $180 \mathrm{~cm}$ height) to ensure access. The control treatment contained only frame without polymethyl-methacrylate sheet. The air temperature was measured minutely using air temperature sensors (HMP155, Vaisala, Helsinki, Finland), and the results showed an average increase of $2.5^{\circ} \mathrm{C}$ in atmospheric temperature during the sampling period (see Supplementary Figure 1). All measured temperatures were stored in data loggers (CR1000, Campbell, NY, Untied States) throughout the plant growing season from June to December 2018. Thus, the 12 subplots were split into four treatments; namely, the natural water level (CK), warming under the natural water level (OTC), warming under the reference water level (the constant water level, about $20-40 \mathrm{~cm}$, based on the suitable water level of the dominant vegetation $)(0 \mathrm{~cm} \times \mathrm{OTC})$, and warming under $10 \mathrm{~cm}$ below the reference water level (the constant water level) $(-10 \mathrm{~cm} \times$ OTC), including interaction designs of water-level and warming (Table 1 and Figure 2).

Before the experiment, 36 soil columns were collected using a PVC pipe $($ diameter $=110 \mathrm{~mm}$, length $=200 \mathrm{~mm}$ ) in a relatively flat wetlands outside the plots to avoid the original differences between plots and to reduce the direct collection of soil samples that could influence our treatments. To prevent species loss during collection, we carefully and immediately wrapped the soil samples with plastic wrap after obtaining them, marked the soil surface, placed the soil columns according to the direction of collecting soil columns, and transported them to the study site. Three soil column samples were placed into one subplot with their plastic wrap removed. The sampling design excluded the dispersal ability of these animals and the possibility of species turnover.

\section{Statistical Analysis}

Abundance data were expressed as numbers per square meter. Diversity indices (Margalef Richness, Pielou Evenness, and Shannon-Wiener index) were calculated in Primer 7.0 to characterize arthropod communities and the influence of warming and water level. The specific formula is as follows: Margalef Richness $\left(M=\frac{(s-1)}{\ln N}\right)$, Shannon-Wiener index $\left(H=-\sum_{i=1}^{s} P_{i} \ln P_{i}\right)$, and Pielou Evenness $(E=H / \ln S)$, where $\mathrm{S}$, total number of species; $\mathrm{N}$, total number of individuals in the sample; $\mathrm{Pi}$, the proportion of the entire community made up of species. Dominance (\%) of a species was expressed as its proportion in the community (dominant, common, and rare species), and the number of individuals of a species was accounted for $>10,1-10$, and $<1 \%$ of the total numbers, respectively. One-way ANOVA analyses were performed to determine the statistical significance of the warming treatment on density measures, the number of species and to test for differences in the diversity indexes between treatments using Tukey's Studentized Range (HSD) test $(p<0.05)$. Figures were created by using Origin 2018 (Origin Lab, Northampton, MA, United States).

Indicator species analysis was based on the abundance of soil springtails and mites under four treatments $(n=3)$ in PCORD Version 5.0, using Dufrene and Legendre's (1997) indicator value method (IVM) (Dai et al., 2006; Iqbal et al., 2018; Kamran et al., 2020). The equations for determining the indicator species were presented in Supplementary Material. Indicator value (IV), ranging from 0 (no indication) to 100 (perfect indication), were tested for statistical significance using a Monte Carlo technique. Only significant species were list $(p<0.05)$ in the results.

\section{RESULTS}

\section{Springtails}

\section{Community Composition and Structure}

The community structure of soil collembola varied significantly across our treatments, with increasing temperature under two constant water level significantly reducing the number of species 


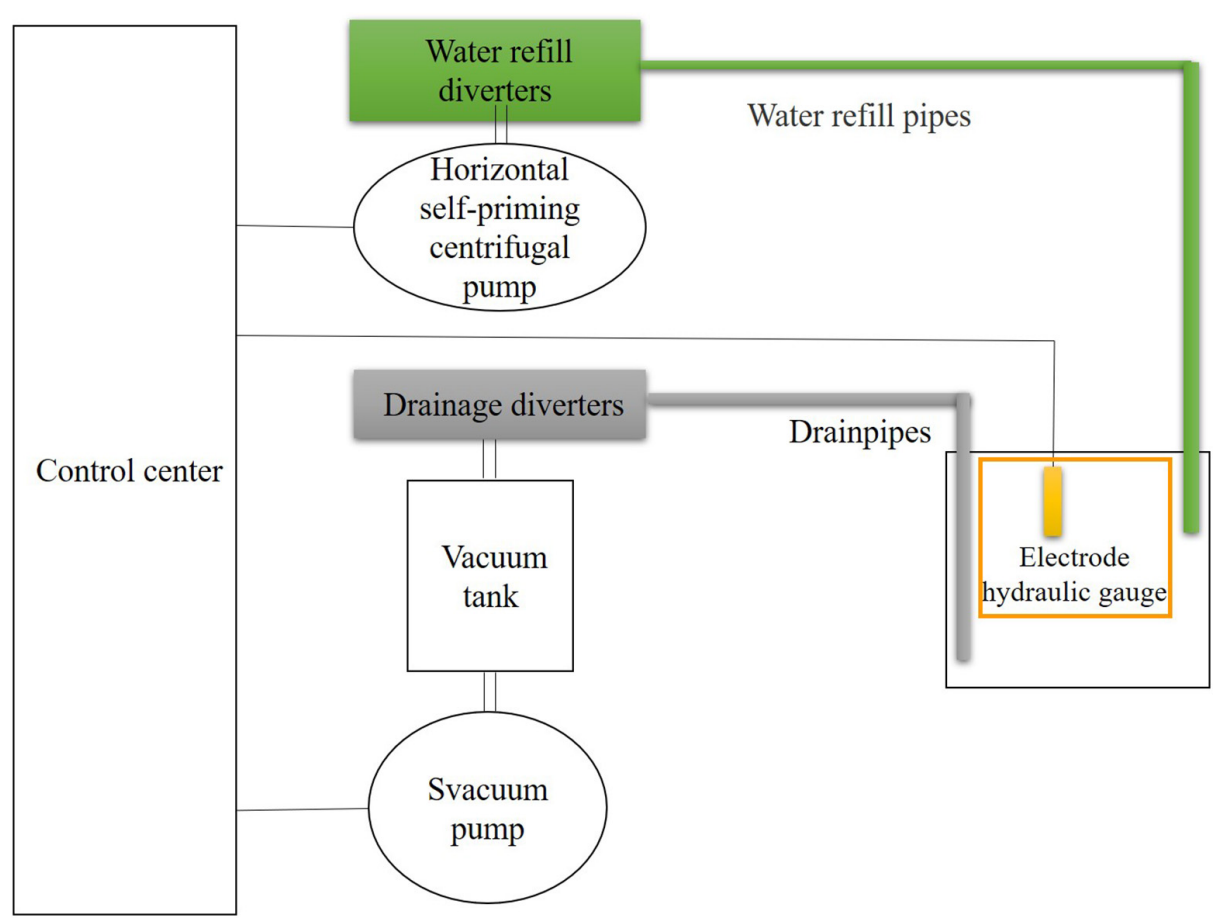

FIGURE 1 | Sketch of automatic water-level control equipment in one subplot (modified from Tan et al., 2018).

TABLE 1 | The design of this experiment.

\begin{tabular}{|c|c|c|c|c|c|}
\hline Treatments & Water level & Warming or not & Replicates & Soil columns & Sampling times \\
\hline CK & The natural water level & No & 3 & 9 & 3 \\
\hline OTC & The natural water level & Yes & 3 & 9 & 3 \\
\hline $\mathrm{O} \mathrm{cm} \times$ OTC & The constant water level & Yes & 3 & 9 & 3 \\
\hline$-10 \mathrm{~cm} \times$ OTC & The constant water level & Yes & 3 & 9 & 3 \\
\hline
\end{tabular}

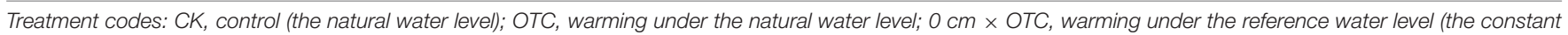

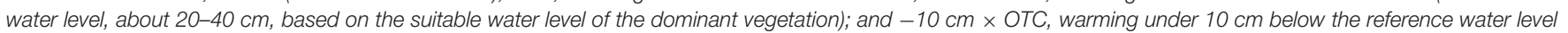
(the constant water level). Soil columns were collected in August, September, and November of 2018, and data were averaged for these analyses.

of collembola (Table 2). There were 20 species identified in the natural water level treatment (CK); the dominant species was Folsomia octoculata, which accounted for $41.86 \%$ of all individuals, while the most common species included Lepidocyrtus szeptyckii, Desoria infuscata, and Anurida maritima. Overall a total of 12 species accounted for $53.02 \%$, with only 7 species accounting for $4.27 \%$. There were also 20 species in the warming treatment (OTC); the dominant species were Desoria olivacea and F. octoculata, accounting for 10.25 and $54.81 \%$, respectively. The common species included Desoria tigrina and Parisotoma ekmani, and an additional seven species accounted for $20.63 \%$. There were 11 rare species, accounting for only $3.85 \%$. There were eight species in total in the warming under $0 \mathrm{~cm}$ water level treatment $(0 \mathrm{~cm} \times \mathrm{OTC})$. D. olivacea, F. octoculata, and Tomocerus nigrus were the dominant species, accounting for $51.65 \%$; there were four common species, accounting for 23.99\%; and D. infuscata was the rarest species, accounting for $0.37 \%$. Finally, there were 13 species in the warming treatment at $-10 \mathrm{~cm}$ water level $(-10 \mathrm{~cm} \times$ OTC $)$. D. olivacea and
F. octoculata were the dominant species, accounting for 18.36 and $63.99 \%$, respectively; common species (14.68\%) included D. tigrina, Vertagopus laricis, and A. maritima, while five rare species accounted for $2.96 \%$.

\section{The Density and Diversity Dynamics of Springtails}

The results of the one-way analysis of variance revealed that the soil collembola density $(F=14.064, p=0.034)$ and the number of species under different treatments $(F=3.832, p=0)$ were significantly different (Figure 3). During warming at the natural water level, the density and number of species were consistently higher than other treatments, with the lowest abundances always present in the warming treatment at the $0 \mathrm{~cm}$ water level. At the same time, the Margalef richness index $(F=10.801$, $p=0.001$ ) of collembola was significantly different under the four treatments, with higher abundances in the natural water level and its warming treatment (Figure 4). Warming at $0 \mathrm{~cm}$ water level treatment had a high uniformity, and the natural water level had high diversity. 


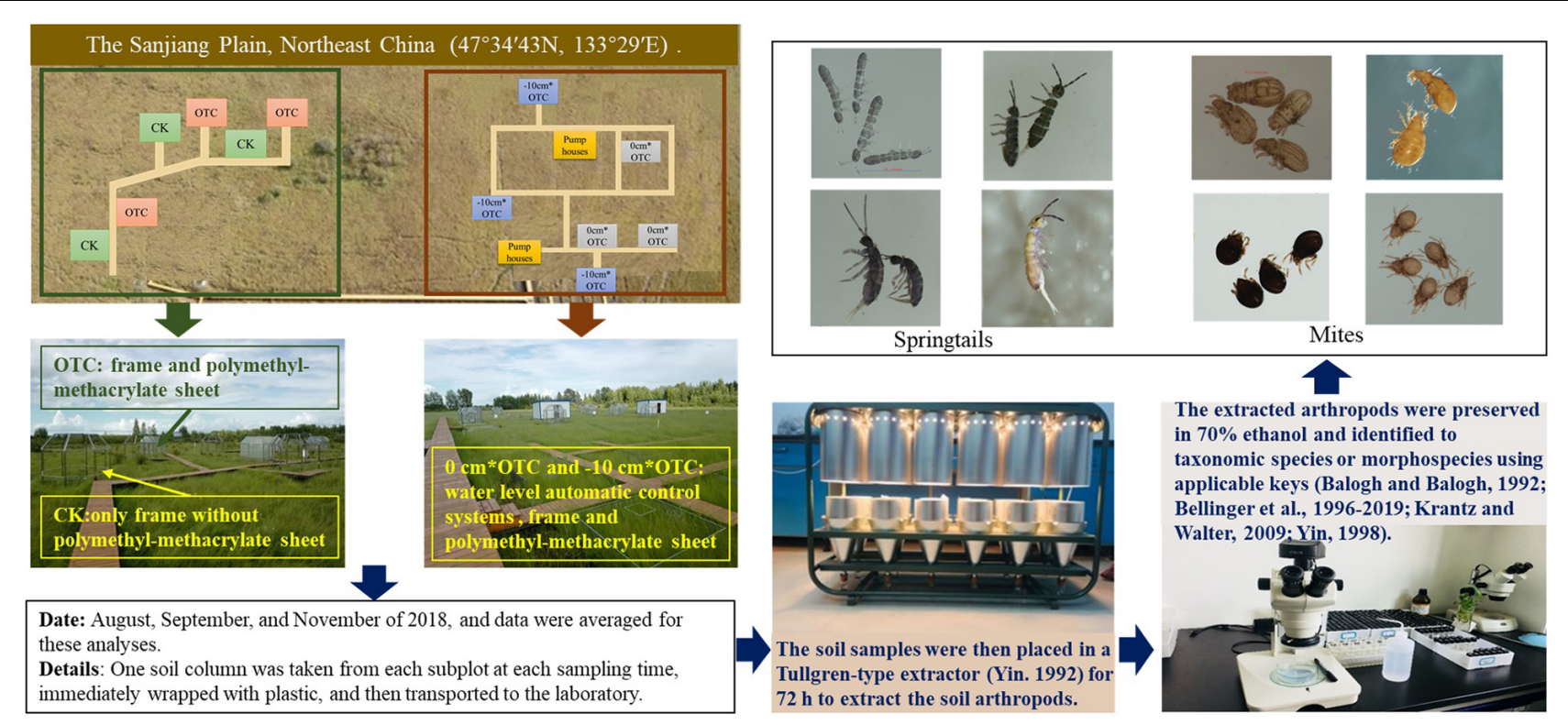

FIGURE 2 | The study site, experimental design, and some kinds of soil microarthropods.

\section{Analysis of Indicator Species}

The indicator species analysis of the four treatments (Table 3) exhibited two indicator species: A. maritima $(p=0.0196)$ in the natural water level and $V$. laricis $(p=0.0172)$ in the warming treatment. Collembola A. maritima existed under the natural water level, warming and warming treatment at $-10 \mathrm{~cm}$ water level (densities were $912 \pm 228,614 \pm 162$, and $246 \pm 35$ ind. $/ \mathrm{m}^{2}$, respectively), but was not present at $0 \mathrm{~cm}$ water level in the warming treatments. The density of $V$. laricis increased significantly after warming $\left(4069 \pm 1187 / \mathrm{m}^{2}\right)$, significantly higher than in the other three treatments were $1789 \pm 914$, $561 \pm 246$, and $316 \pm 0$ ind. $/ \mathrm{m}^{2}$, respectively.

\section{Mites}

\section{Community Composition and Structure}

A total of 1290 mites were captured in three samplings in 2018, belonging to nine families and ten genera (Table 1). The dominant species were Geolaelaps praesternaliodes, Malaconothrus tardus, and Zetomimus furcatus, which accounted for $32.48,37.52$, and $13.72 \%$ of all individuals, respectively. Common species include Cheiroseius sinicus and Geolaelaps dailingensis, accounting for $15.12 \%$ of the total catch, while four rare species accounted for only $1.16 \%$.

There were also significant differences in the community composition of soil mites under various treatments (Table 2). There were nine species identified under the natural water level. The dominant species were G. praesternaliodes, M. tardus, and Z. furcatus, accounting for $37.25,33.04$, and $10.20 \%$, respectively; five common species accounted for $19.24 \%$; Belba compta was a rare species that only accounted for $0.44 \%$. After warming treatment, there were eight species. The dominant species were consistent with the natural water level plots, but the proportions varied, respectively, $33.33,29.17$, and $24.56 \%$; there were three common species, accounting for $11.84 \%$. The other two species were rare, accounting for $1.10 \%$. There were eight kinds of warming treatments under $0 \mathrm{~cm}$ water level. Compared with the first two treatments, the dominant species ( $Z$. furcatus) was significantly reduced; there were three common taxa, accounting for $19.74 \%$, and the remaining two species were rare, accounting for $0.86 \%$. There were eight species after warming at $-10 \mathrm{~cm}$ water level. Compared with the dominant species at $0 \mathrm{~cm}$ water level, the dominant species accounted for 52 and $31.33 \%$, respectively; common species included C. sinicus and Banksinoma akhtyamovi. Four species accounted for $15.33 \%$ of the total catch, and two rare species accounted for $1.16 \%$ of the total catch.

\section{The Density and Diversity Dynamics of Mites}

According to the Shannon-Wiener diversity index $(F=3.904$, $p=0.032$ ), there were also significant differences across treatments, with a significantly higher diversity of mites under natural water level and warming treatment, than under warming at $0 \mathrm{~cm}$ water level (Figure 5). Although, the soil mites density $(F=0.387, p=0.764)$, number of species $(F=1.379, p=0.290)$, Pielou evenness index $(F=2.532, p=0.099)$, and Margalef richness index $(F=1.062, p=0.397)$ did not significantly differ (Figures 5, 6). The natural water level had higher uniformity and diversity than increasing temperatures under the $0 \mathrm{~cm}$ water level.

\section{Indicator Species Analysis}

There were two indicator species of mites, C. sinicus $(p=0.0426)$ and M. tardus ( $p=0.0022)$ (Table 3). The density of $C$. sinicus under the four treatments were $631 \pm 192,263 \pm 71,1052 \pm 219$, and $281 \pm 126 \mathrm{ind} . / \mathrm{m}^{2}$. The density of $M$. tardus under the four treatments was $2613 \pm 562,2333 \pm 596,5437 \pm 345$, and $1649 \pm 345$ ind. $/ \mathrm{m}^{2}$. 
TABLE 2 | Soil microarthropod community composition and dominance in four treatments $(n=3)$ in the Sanjiang Plain

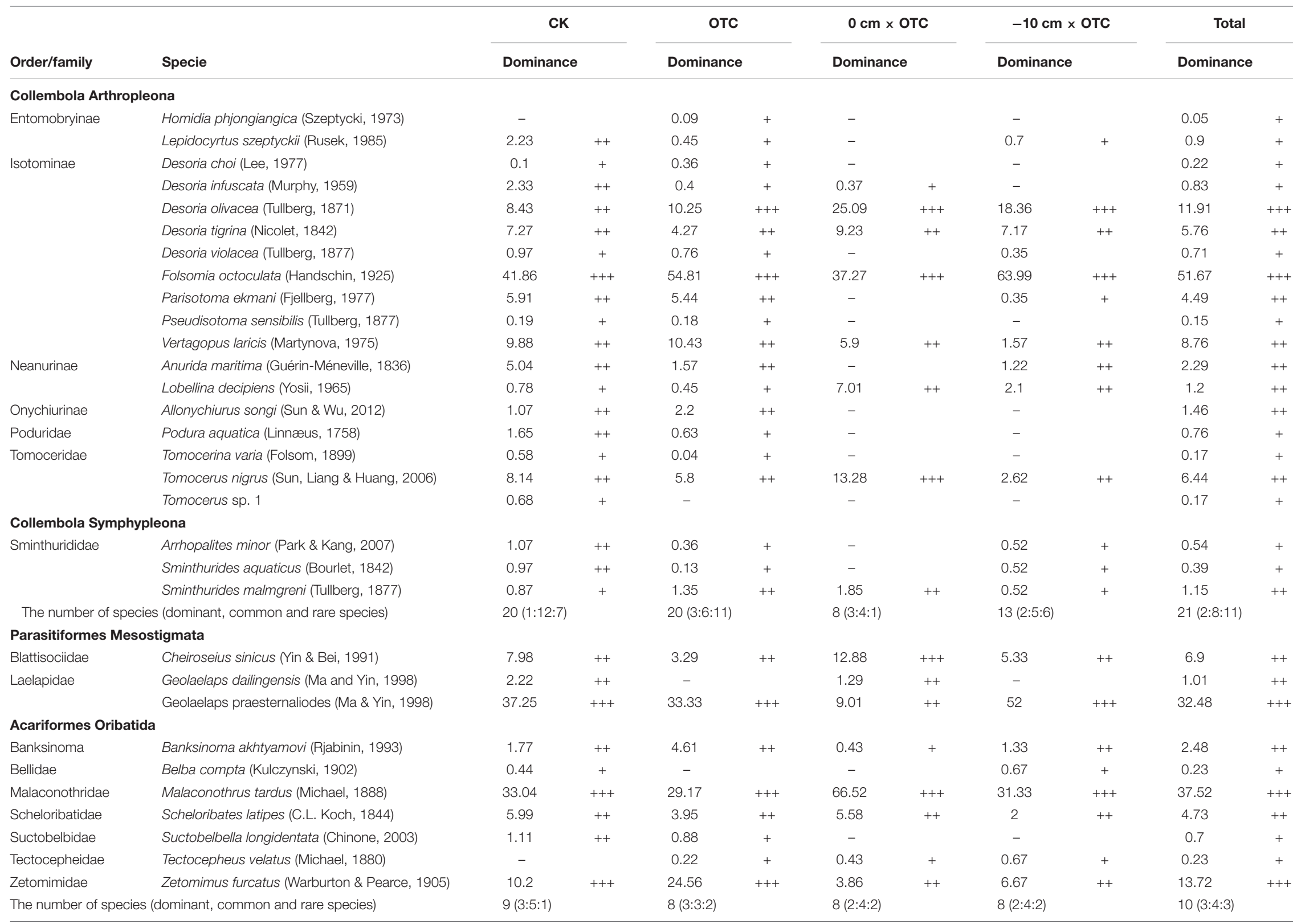

The dominance of the Collembola and Oribatida was calculated separately. 

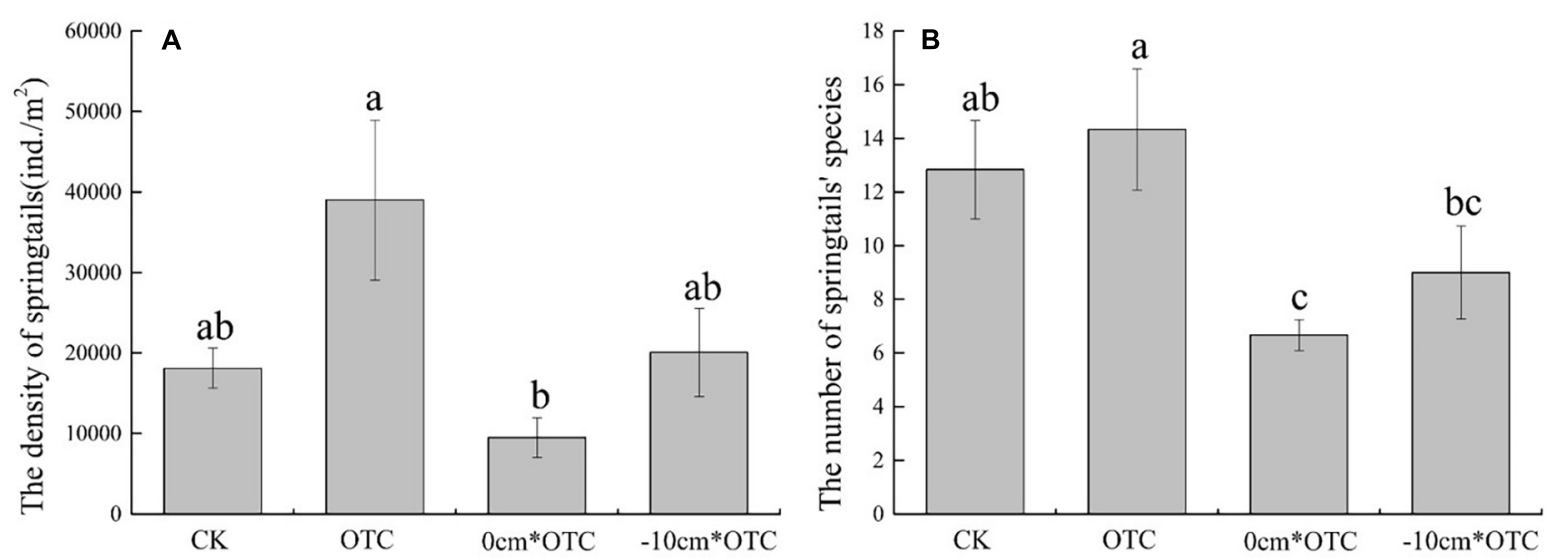

FIGURE 3 | Soil springtail density (A) and number of species (B) in different treatments. Data are means \pm SE $(n=3)$ and different letters indicate significant differences between treatments $(\mathrm{a}, \mathrm{b}$, and $\mathrm{c})$ at $p<0.05$.
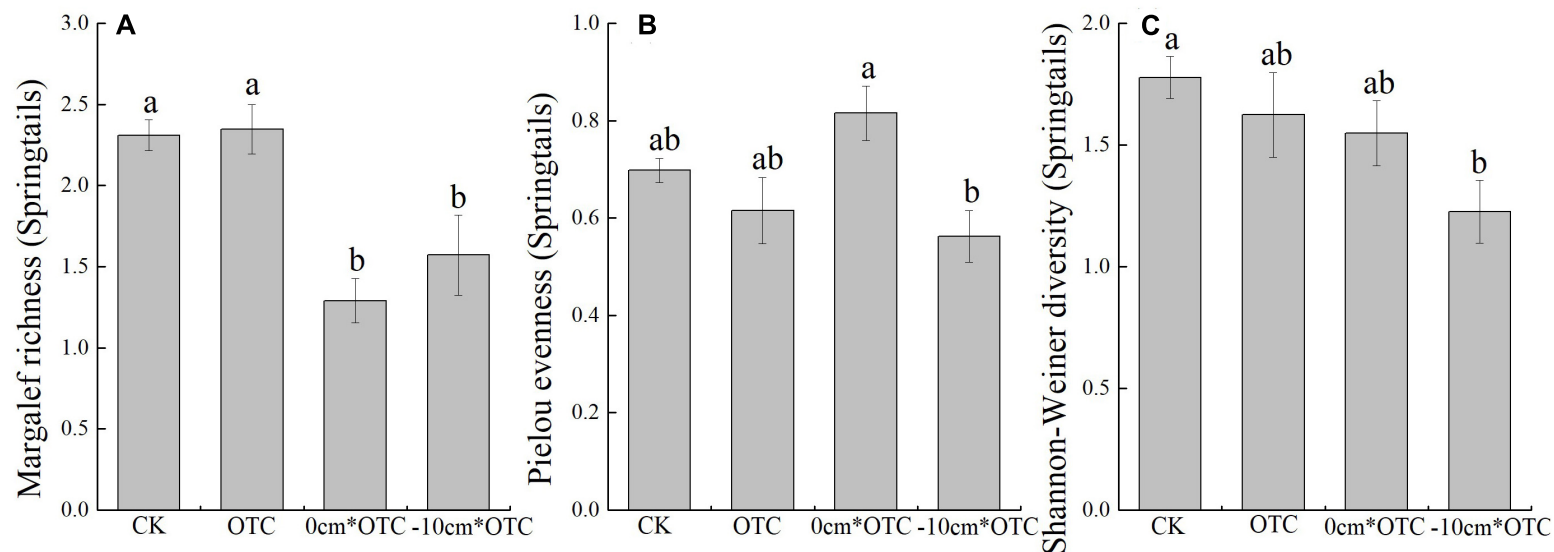

FIGURE 4 | Soil springtail diversity indexes in different treatments: (A) Margalef richness, (B) Pielou evenness, and (C) Shannon-Wiener index. Data are means \pm SE $(n=3)$ and different letters indicate significant differences between treatments (a and b) at $p<0.05$.

TABLE 3 | Indicator species analysis of four treatments in the Sanjiang Plain marshlands.

\begin{tabular}{|c|c|c|c|}
\hline Treatments & Indicator species & Indicator value & $p$ \\
\hline OTC & Vertagopus laricis (Martynova, 1975) (Springtails) & 60.4 & 0.0172 \\
\hline CK & Anurida maritima (Guérin-Méneville, 1836) (Springtails) & 51.5 & 0.0196 \\
\hline $\mathrm{O} \mathrm{cm} \times$ OTC & Cheiroseius sinicus (Yin \& Bei, 1991) (Mites) & 47.2 & 0.0426 \\
\hline $\mathrm{O} \mathrm{cm} \times$ OTC & Malaconothrus tardus (Michael, 1888) (Mites) & 45.2 & 0.0022 \\
\hline
\end{tabular}

Only significant species were list, $p<0.05$.

\section{DISCUSSION}

Our results demonstrate that single and combined effects of warming and drainage can influence soil microarthropod's abundance and community structure, which are important regulators of ecosystem processes. Further, we found that the major taxonomic groups of soil microarthropods, i.e., collembola and mites, differed in their response to our climate change treatments, which appears to be more complex than we assumed. Besides, the results confirmed our hypothesis that warming alone slightly increased the density and abundance of springtails (CK vs. OTC). It supports the view that warming in humid areas has a positive effect or no effect on soil fauna. And the synergistic effect of warming and drainage also increased the density and abundance of springtails $(0 \mathrm{~cm} \times$ OTC vs. $-10 \mathrm{~cm} \times$ OTC).

Previous studies have identified that 3 years of temperature increases have significantly increased the abundance of total collembola and its dominant species Orchesellides sp1 in the Songnen Grasslands (Yan et al., 2015). In this study, warming under different water levels impacted the community 

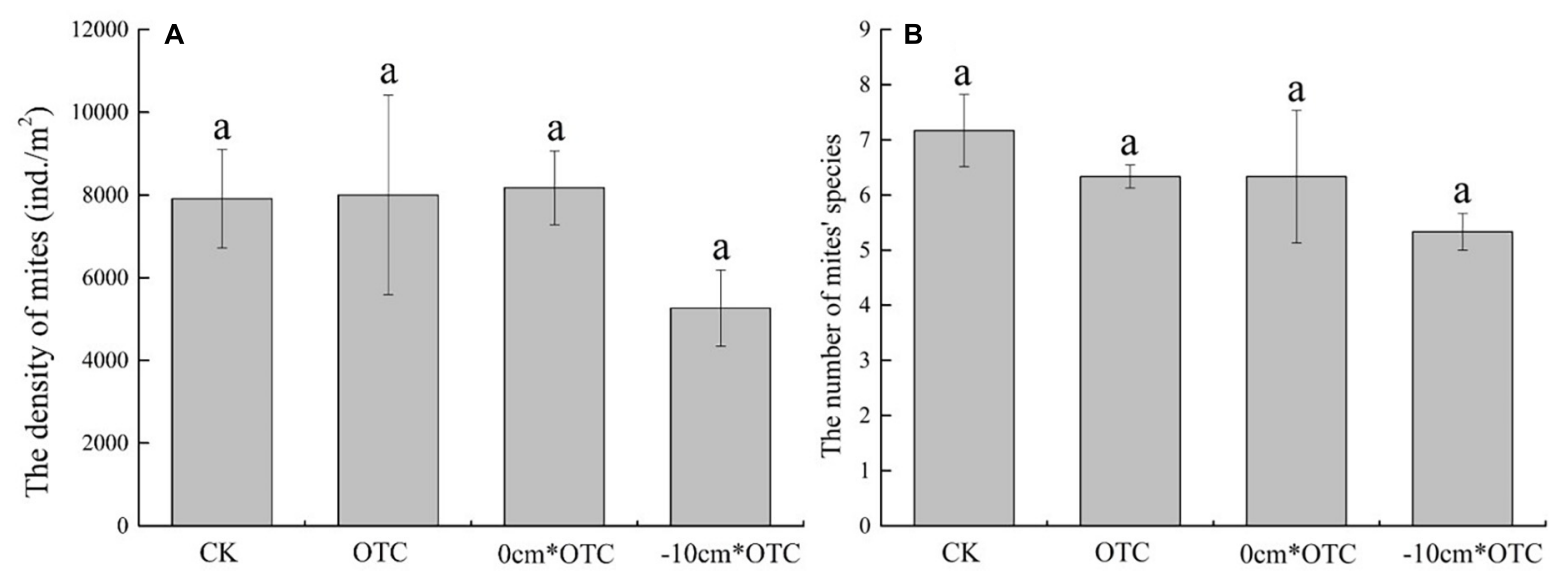

FIGURE 5 | Soil mites density (A) and number of species $\mathbf{( B )}$ in different treatments. Data are means \pm SE $(n=3)$, and the same letter indicate insignificant differences between treatments (a) at $p<0.05$.
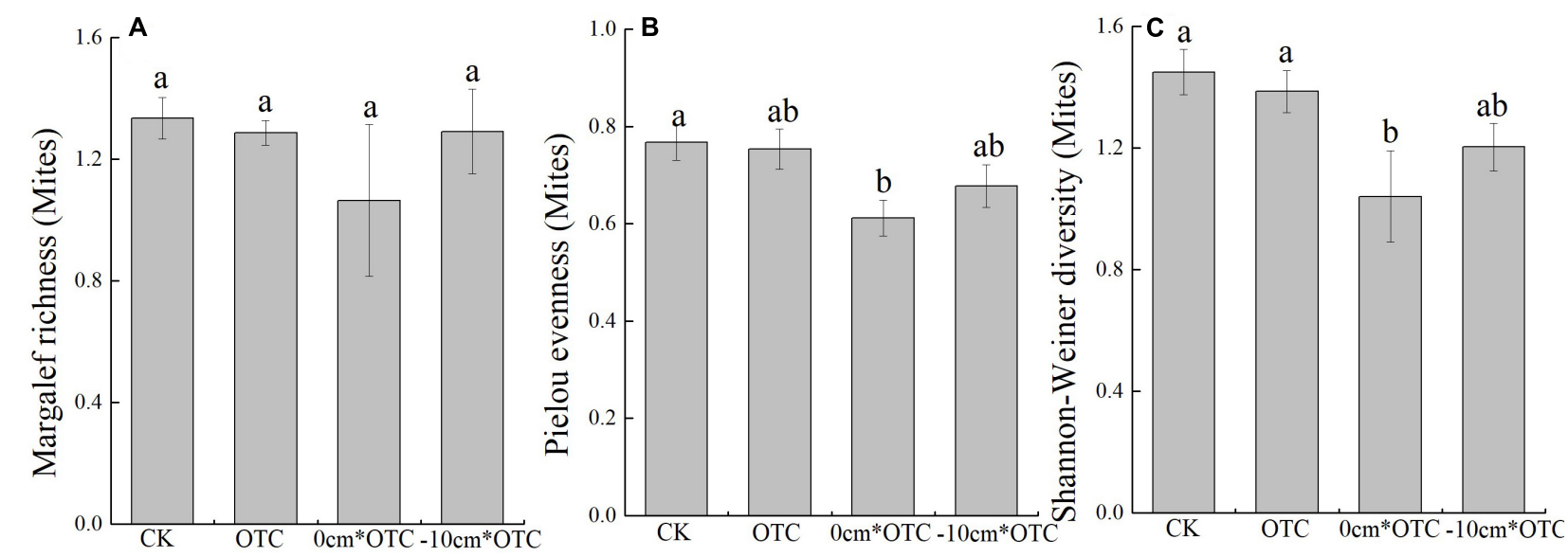

FIGURE 6 | Soil mites diversity indexes in different treatments: (A) Margalef richness, (B) Pielou evenness, and (C) Shannon-Wiener index. Data are means \pm SE $(n=3)$ and different letters indicate significant differences between treatments (a and b) at $p<0.05$.

composition of soil microarthropods in the marsh of the Sanjiang Plain, which may influence ecosystem functioning. Warming has also increased the density of collembola under the natural water levels. Conversely, other studies found that increasing temperatures can result in decreasing population densities of Prostigmata (Briones et al., 2009), nematodes (Simmons et al., 2009; Mueller et al., 2016), and springtails (Holmstrup et al., 2017). However, variation in these ecosystems could explain these differences. Compared with the natural water level, the number of collembola species decreased from 20 to 8 species under the temperature increase at $0 \mathrm{~cm}$ water level. Makkonen et al. (2011) also found that increased temperature reduced the number of collembola species in subarctic regions, decreasing from 14 species to 12 . This may result from some species of springtails being unable to adapt to the changing environment when faced with temperature change, inducing the migration or death of species. Many previous studies have also shown that the adverse effects of warming on soil fauna may be caused by decreased soil moisture concentrations (Xu et al., 2012; Chang et al., 2019). Due to the increase in vegetation and soil surface evaporation, the increase in temperature usually leads to a dry environment, resulting in shifts in the composition of the collembola community to a low-water preference species. Compared with springtails, the number of species of oribatid varied less after treatment exposure, displaying a greater ability to adapt. In the context of warming, it often appears that springtails are more influenced by warming than mites in some ecosystems, but the opposite is also apparent in other ecosystems (Blankinship et al., 2011; Bokhorst et al., 2017).

Soil fauna can represent suitable indicator organisms for evaluating soil quality, soil biological effects, ecosystem succession, or the degree of disturbance (David and Gillon, 2009; Shao et al., 2015; Venuste et al., 2018; Srut et al., 2019). Indicator species analysis based on the abundance of soil springtails and mites under four treatments helped us to screen out four indicator species. The density of A. maritima (springtail) was 
significantly reduced at the constant water level. A. maritima (springtail) had the highest density after the warming at the natural fluctuating water levels, demonstrating adaptability to warming. Two species of mites, C. sinicus and M. tardus, were indicators in the $0 \mathrm{~cm}$ water level warming treatment. Their densities were significantly higher than in the other treatment groups, exhibiting tolerance to warming and constant water level.

Drainage and water level fluctuation impact the community composition and diversity of plants and soil fauna. The relationship between water level change and plant population characteristics, species diversity and life history have been studied. Researches showed that fluctuation and its frequency are important factors affecting the growth, reproduction, and population distribution of wetland plants (Gattringer et al., 2018; Yao et al., 2021). Water fluctuation increased number of shoot nodes and shoot length of the communities, and may increase the vegetative spread of submerged macrophyte communities (Wang et al., 2016), and biomass accumulation in roots rather than in shoots and the ability to asexually propagate were important for the survival of these species during water fluctuation (Wei et al., 2019). Short-term decline of the water table may increase the primary productivity by shifting dominant species of hygrophytes to mesophytes in the Zogie wetlands (Cao et al., 2017). Meanwhile, plant diversity or functional characteristics often lead to changes in soil fauna resources and habitat environment. Collembola density and diversity significantly increased with plant species and plant functional group richness (Eisenhauer et al., 2011; Sabais et al., 2011). In forest area, the mean species richness of the collembolan communities increased by $47 \%$, when the number of plant species increased from one (spruce) to three (spruce beech and fir) (Chauvat et al., 2011). In this study, the density, species number and abundance of springtails under the natural water level and its warming treatment were significantly higher than the warming treatment under the constant water level. This increase was also observed in the diversity of mites. This phenomenon were likely due to increased root and microbial biomass in the natural water level, and elevated quantity and quality of plant residues serving as food resources for springtails and mites. It is also recommended that the natural water level fluctuations of the wetland should be maintained, when wetland restoration is conducted under the influence of future warming. Otherwise, we were aware of this study also had deficiencies. A long-term, comprehensive research is needed for indicating the effect of warming and water level on wetland plants, soil fauna, and soil properties.

\section{CONCLUSION}

After the wetlands, under different water levels, in the Sanjiang Plain were warmed, the composition of the soil microarthropod community was significantly changed. Warming increased the density and richness of collembola under the natural water level, but decreased the density and richness of springtails under the constant water level. The diversity of mites under the natural water level and its warming treatment was significantly higher than that of the warming treatment at the $0 \mathrm{~cm}$ water level.
Besides, A. maritima and $V$. laricis, two indicators for the natural water level, had the highest densities in the natural water level and warming under the natural water level, respectively. C. sinicus and $M$. tardus had the highest densities in warming under the $0 \mathrm{~cm}$ water level, significantly higher than the other three treatments. We have also shown that in the context of global warming, maintaining natural water level fluctuations is of great significance to the composition and diversity of soil microarthropod communities.

\section{DATA AVAILABILITY STATEMENT}

The original contributions presented in the study are included in the article/Supplementary Material, further inquiries can be directed to the corresponding author.

\section{AUTHOR CONTRIBUTIONS}

$\mathrm{HZ}$ performed the field investigation, collected the data, conducted the statistical analysis, and wrote the manuscript. XS and DL carried on the classification and identification to the collembola and mites, respectively. HW designed the study and, reviewed and edited the manuscript. HC provided pertinent comments, improved the discussion, and polished the article. All authors read and approved the final manuscript.

\section{FUNDING}

This study was supported by the National Natural Science Foundation of China Joint Fund (Regional Innovation and Development Joint Fund) (U20A2083), the National Key R\&D Program of China (2017YFC0505901), the National Natural Science Foundation of China (41671260 and 41871099), and Jilin Scientific and Technological Development Program (20180101080JC).

\section{ACKNOWLEDGMENTS}

We are grateful to Qiang Guan, Kangle Lu, and Ke Zhang from Northeast Institute of Geography and Agroecology, Chinese Academy of Sciences for sampling.

\section{SUPPLEMENTARY MATERIAL}

The Supplementary Material for this article can be found online at: https://www.frontiersin.org/articles/10.3389/fevo.2021. 731735/full\#supplementary-material

Supplementary Figure 1 | Air temperature time-series within or outside the open-top chambers in natural water level during the experiment. 


\section{REFERENCES}

Balogh, J., and Balogh, P. (1992). The Oribatid Mite Genera of the World. vol. 1. Budapest: Hungarian Natural History Museum, 1-263.

Bellinger, P. F., Christiansen, K. A., and Janssens, F. (1996-2019). Checklist of the Collembola of the World. Available online at: http://www.collembola.org (accessed 1996).

Blankinship, J. C., Niklaus, P. A., and Hungate, B. A. (2011). A meta-analysis of responses of soil biota to global change. Oecologia 165, 553-565. doi: 10.1007/ s00442-011-1909-0

Bokhorst, S., Convey, P., Huiskes, A., Van Bodegom, P. M., and Aerts, R. (2017). Dwarf shrub and grass vegetation resistant to long-term experimental warming while microarthropod abundance declines on the Falkland Islands. Austral Ecol. 42, 984-994. doi: 10.1111/aec.1 2527

Briones, M. J. I., Ostle, N. J., Mcnamara, N. P., and Poskitt, J. (2009). Functional shifts of grassland soil communities in response to soil warming. Soil Biol. Biochem. 41, 315-322. doi: 10.1016/j.soilbio.2008.11.003

Brussaard, L. (1998). Soil fauna, guilds, functional groups and ecosystem processes. Appl. Soil Ecol. 9, 123-135. doi: 10.1016/s0929-1393(98)00066-3

Cao, R., Wei, X., Yang, Y., Xi, X., and Wu, X. (2017). The effect of water table decline on plant biomass and species composition in the Zoige peatland: a four-year in situ field experiment. Agric. Ecosyst. Environ. 247, 389-395. doi: 10.1016/j.agee.2017.07.008

Chang, L., Wang, B., Yan, X., Ma, L., Reddy, G. V. P., and Wu, D. (2019). Warming limits daytime but not nighttime activity of epigeic microarthropods in Songnen grasslands. Appl. Soil Ecol. 141, 79-83. doi: 10.1016/j.apsoil.2019. 05.012

Chauvat, M., Titsch, D., Zaytsev, A. S., Zaytsev, A. S., and Wolters, V. (2011). Changes in soil faunal assemblages during conversion from pure to mixed forest stands. For. Ecol. Manag. 262, 317-324. doi: 10.1016/j.foreco.2011.03.037

Dai, X., Page, B., and Duffy, K. J. (2006). Indicator value analysis as a group prediction technique in community classification. South Afr. J. Bot. 72, 589-596. doi: $10.1016 /$ j.sajb.2006.04.008

Darby, B. J., and Neher, D. A. (2012). Stable isotope composition of microfauna supports the occurrence of biologically fixed nitrogen from cyanobacteria in desert soil food webs. J. Arid Environ. 85, 76-78.

David, J.-F., and Gillon, D. (2009). Combined effects of elevated temperatures and reduced leaf litter quality on the life-history parameters of a saprophagous macroarthropod. Global Change Biol. 15, 156-165. doi: 10.1111/j.1365-2486. 2008.01711.x

Dufrene, M., and Legendre, P. (1997). Species assemblages and indicator species: the need for a flexible asymmetrical approach. Ecol. Monogr. 67, 345-366. doi: $10.2307 / 2963459$

Eisenhauer, N., Milcu, A., Sabais, A. C. W., Bessler, H., Brenner, J., Engels, C., et al. (2011). Plant diversity surpasses plant functional groups and plant productivity as driver of soil biota in the long term. PLoS One 6:e16055. doi: 10.1371/journal. pone. 0016055

Gattringer, J. P., Ludewig, K., Harvolk-Schoning, S., Donath, T. W., and Otte, A. (2018). Interaction between depth and duration matters: flooding tolerance of 12 floodplain meadow species. Plant Ecol. 219, 973-984. doi: 10.1007/s11258018-0850-2

Geisen, S., and Bonkowski, M. (2018). Methodological advances to study the diversity of soil protists and their functioning in soil food webs. Appl. Soil Ecol. 123, 328-333. doi: 10.1016/j.apsoil.2017.05.021

Hallam, J., and Hodson, M. E. (2020). Impact of different earthworm ecotypes on water stable aggregates and soil water holding capacity. Biol. Fertil. Soils 56, 607-617. doi: 10.1007/s00374-020-01432-5

Holmstrup, M., Damgaard, C., Schmidt, I. K., Arndal, M. F., Beier, C., and Mikkelsen, T. N. (2017). Long-term and realistic global change manipulations had low impact on diversity of soil biota in temperate heathland. Sci. Rep. $7: 11$.

Iqbal, M., Khan, S. M., Khan, M. A., Ahmad, Z., and Ahmad, H. (2018). A novel approach to phytosociological classification of weeds flora of an agro-ecological system through Cluster, Two Way Cluster and Indicator Species Analyses. Ecol. Indic. 84, 590-606. doi: 10.1016/j.ecolind.2017.09.023

Kamran, S., Khan, S. M., Ahmad, Z., Rahman, A. U., Iqbal, M., Manan, F., et al. (2020). The role of graveyards in species conservation and beta diversity: a vegetation appraisal of sacred habitats from Bannu, Pakistan. J. For. Res. 31, 1147-1158. doi: 10.1007/s11676-019-00893-1

Kardol, P., Reynolds, W. N., Norby, R. J., and Classen, A. T. (2011). Climate change effects on soil microarthropod abundance and community structure. Appl. Soil Ecol. 47, 37-44. doi: 10.1016/j.apsoil.2010.11.001

Koltz, A. M., Classen, A. T., and Wright, J. P. (2018). Warming reverses top-down effects of predators on belowground ecosystem function in Arctic tundra. Proc. Natl. Acad. Sci. U.S.A. 115, E7541-E7549.

Krantz, G. W., and Walter, D. E. (2009). A Manual of Acarology. Lubbock, TX: Texas Tech University Press.

Liang, W. J., Ge, T. K., and Duan, Y. X. (2001). Bioindication of soil fauna to soil health. J. Shenyang Agric. Univ. 32, 70-72.

Lindberg, N. (2003). Soil Fauna and Global Change (Responses to Experimental Drought, Irrigation, Fertilisation and Soil Warming). Swedish University of Agricultural Sciences. Doctoral Thesis. Uppsala: Swedish University of Agricultural Sciences.

Liu, W. P. A., Janion, C., and Chown, S. L. (2012). Collembola diversity in the critically endangered Cape Flats Sand Fynbos and adjacent pine plantations. Pedobiologia 55, 203-209. doi: 10.1016/j.pedobi.2012.0 3.002

Liu, X. (2016). Effects of Climate Change on the Net Primary Productivity of Wetlands in Sanjiang Plain. Doctoral Thesis. Changchun.

Liu, X. H., Zhang, Y., Dong, G. H., and Jiang, M. (2019). Difference in carbon budget from marshlands to transformed paddy fields in the Sanjiang Plain, Northeast China. Ecol. Eng. 137, 60-64. doi: 10.1016/j.ecoleng.2018.03.013

Makkonen, M., Berg, M. P., Van Hal, J. R., Callaghan, T. V., Press, M. C., and Aerts, R. (2011). Traits explain the responses of a sub-arctic Collembola community to climate manipulation. Soil Biol. Biochem. 43, 377-384. doi: 10.1016/j.soilbio. 2010.11.004

Meng, H. (2016). Research on the Impact of Climate Change on the Marsh Distribution and its Risk Assessment in the Sanjiang Plain. Doctoral Thesis. Changchun.

Mueller, K. E., Blumenthal, D. M., Carrillo, Y., Cesarz, S., Ciobanu, M., and Hines, J. (2016). Elevated CO2 and warming shift the functional composition of soil nematode communities in a semiarid grassland. Soil Biol. Biochem. 103, 46-51. doi: 10.1016/j.soilbio.2016.08.005

Oliverio, A. M., Geisen, S., Delgado-Baquerizo, M., Maestre, F. T., Turner, B. L., and Fierer, N. (2020). The global-scale distributions of soil protists and their contributions to belowground systems. Sci. Adv. 6:Eaax8787. doi: 10.1126/ sciadv.aax 8787

Phillips, H. R. P., Guerra, C. A., Bartz, M. L. C., Briones, M. J. I., Brown, G., Crowther, T. W., et al. (2019). Global distribution of earthworm diversity. Science 366, 480-485.

Phillips, H. R. P., Heintz-Buschart, A., and Eisenhauer, N. (2020). Putting soil invertebrate diversity on the map. Mol. Ecol. 29, 655-657. doi: 10.1111/mec. 15371

Sabais, A. C. W., Scheu, S., and Eisenhauer, N. (2011). Plant species richness drives the density and diversity of Collembola in temperate grassland. Acta Oecol. Int. J. Ecol. 37, 195-202. doi: 10.1016/j.actao.2011.02.002

Semenina, E. E., and Tiunov, A. V. (2020). Assimilation of aboveground litter carbon versus soil carbon by Collembola and Lumbricidae in spruce forest: a litter replacement experiment. Polish J. Ecol. 68, 172-180.

Shao, Y. H., Zhang, W. X., Liu, S. J., Wang, X. L., and Fu, S. L. (2015). Diversity and function of soil fauna. Acta Ecol. Sin. 35, 6614-6625.

Shen, X. J., Liu, B. H., Xue, Z. S., Jiang, M., Lu, X. G., and Zhang, Q. (2019a). Spatiotemporal variation in vegetation spring phenology and its response to climate change in freshwater marshes of Northeast China. Sci. Total Environ. 666, 1169-1177. doi: 10.1016/j.scitotenv.2019.02.265

Shen, X. J., Xue, Z. S., Jiang, M., and Lu, X. G. (2019b). Spatiotemporal change of vegetation coverage and its relationship with climate change in freshwater marshes of Northeast China. Wetlands 39, 429-439. doi: 10.1007/s13157-0181072-z

Simmons, B. L., Wall, D. H., Adams, B. J., Ayres, E., Barrett, J. E., and Virginia, R. A. (2009). Long-term experimental warming reduces soil nematode populations in the McMurdo Dry Valleys, Antarctica. Soil Biol. Biochem. 41, 2052-2060. doi: 10.1016/j.soilbio.2009.07.009

Srut, M., Menke, S., Hockner, M., and Sommer, S. (2019). Earthworms and cadmium - Heavy metal resistant gut bacteria as indicators for heavy metal 
pollution in soils? Ecotoxicol. Environ. Saf. 171, 843-853. doi: 10.1016/j.ecoenv. 2018.12.102

Sun, X., Li, Q., Yao, H. F., Liu, M. Q., Wu, D. H., Zu, D., et al. (2021). Soil fauna and soil health. Acta Pedol. Sin. 58, 1073-1083.

Tan, W. W., Sun, Y., Song, C. C., Zhang, X. H., Han, Z., and Qiao, T. H. (2018). Design and construction of water-level and air temperature co-regulated plot in sanjiang plain experimental station of wetland ecology. Chin. Acad. Sci. Wetland Sci. 16, 114-119.

van den Hoogen, J., Geisen, S., Routh, D., Ferris, H., Traunspurger, W., Wardle, D. A., et al. (2019). Soil nematode abundance and functional group composition at a global scale. Nature 572, 194-198.

Vazquez, E., Teutscherova, N., Lojka, B., Arango, J., and Pulleman, M. (2020). Pasture diversification affects soil macrofauna and soil biophysical properties in tropical (silvo)pastoral systems. Agric. Ecosyst. Environ. 302:107083. doi: 10.1016/j.agee.2020.107083

Venuste, N., Beth, K. A., Frederic, F., Lombart, K. M. M., Wouter, D., and Donat, N. (2018). Use of soil and litter ants (Hymenoptera: Formicidae) as biological indicators of soil quality under different land uses in Southern Rwanda. Environ. Entomol. 47, 1394-1401.

Wang, P., Zhang, Q., Xu, Y. S., and Yu, F. H. (2016). Effects of water level fluctuation on the growth of submerged macrophyte communities. Flora 223, 83-89. doi: 10.1016/j.flora.2016.05.005

Wang, S. J., and Ran, H. H. (2008). Feedback mechanisms of soil biota to aboveground biology in terrestrial ecosystems. Biodriversity Sci. 16, 407-416. doi: 10.3724/sp.j.1003.2008.07356

Wardle, D. A., Williamson, W. M., Yeates, G. W., and Bonner, K. I. (2005). Trickledown effects of aboveground trophic cascades on the soil food web. Oikos 111, 348-358. doi: 10.1111/j.0030-1299.2005.14092.x

Wei, G. W., Chen, Y., Sun, X. S., Chen, Y. H., Luo, F. L., and Yu, F. H. (2019) Growth responses of eight wetland species to water level fluctuation with different ranges and frequencies. PLoS One 14:e0220231. doi: 10.1371/journal. pone. 0220231

Wu, T., Su, F., Han, H., Du, Y., Yu, C., and Wan, S. (2014). Responses of soil microarthropods to warming and increased precipitation in a semiarid temperate steppe. Appl. Soil Ecol. 84, 200-207.
Xu, G. L., Kuster, T. M., Gunthardt-Goerg, M. S., Dobbertin, M., and Li, M. H. (2012). Seasonal exposure to drought and air warming affects soil Collembola and mites. PLoS One 7:e43102. doi: 10.1371/journal.pone.004 3102

Yan, X., Ni, Z., Chang, L., Wang, K., and Wu, D. (2015). Soil warming elevates the abundance of Collembola in the songnen plain of China. Sustainability 7, 1161-1171. doi: 10.3390/su7021161

Yao, X. C., Cao, Y., Zheng, G. D., Devlin, A. T., Li, X., Li, M. H., et al. (2021). Ecological adaptability and population growth tolerance characteristics of Carex cinerascens in response to water level changes in Poyang Lake, China. Sci. Rep. 11:4887.

Yin, W. Y. (1992). Subtropical Soil Animals of China. Beijing: Science Press. Yin, W. Y. (1998). Pictorial Keys to Soil Animals of China. Beijing: Science Press. Zhang, H., and Wu, H. T. (2020). Research progresses in effects of climate warming on soil fauna community structure. Chin. J. Ecol. 39, 655-664.

Zhang, J. Q., Zhang, B., Ma, B., Cao, B., Liang, J. J., and Ma, S. Q. (2019). Spatialtemporal variation of NDVI in Sanjiang Plain and its response to climate change. J. Desert Res. 39, 206-213.

Conflict of Interest: The authors declare that the research was conducted in the absence of any commercial or financial relationships that could be construed as a potential conflict of interest.

Publisher's Note: All claims expressed in this article are solely those of the authors and do not necessarily represent those of their affiliated organizations, or those of the publisher, the editors and the reviewers. Any product that may be evaluated in this article, or claim that may be made by its manufacturer, is not guaranteed or endorsed by the publisher.

Copyright (c) 2021 Zhang, Sun, Liu, Wu and Chen. This is an open-access article distributed under the terms of the Creative Commons Attribution License (CC BY). The use, distribution or reproduction in other forums is permitted, provided the original author(s) and the copyright owner(s) are credited and that the original publication in this journal is cited, in accordance with accepted academic practice. No use, distribution or reproduction is permitted which does not comply with these terms. 